\title{
AN ASSESSMENT OF A RIVER HYDROLOGICAL REGIME ALTERATION: A CASE STUDY OF SUNGAI DUNGUN
}

\author{
AHMAD NABIL MOHD ZAMRI ${ }^{1}$, MOHD SOFIYAN SULAIMAN ${ }^{*}$, SAFURA MAD JUHARI ${ }^{2}$ \\ AND NIK NURHAZIRAH NIK OMAR ${ }^{2}$
}

${ }^{1}$ Faculty Ocean Engineering Technology and Informatics, Universiti Malaysia Terengganu, 21300 Kuala Nerus, Terengganu, Malaysia

${ }^{2}$ Lembaga Sumber Air Negeri Terengganu (LAUT), Wisma Negeri, 20200 Kuala Terengganu, Malaysia

* Corresponding author: sofiyan@umt.edu.my

http://doi.org/10.46754/umtjur.2021.07.016

\begin{abstract}
Hydro-morphology of a river can be assessed using four main methods namely morphological assessment, physical habitat assessment, riparian habitat assessment and hydrological regime alteration assessment. This study focused on the fourth method where changes in flow rate are the criteria of river regime alteration. The Indicator of Hydrologic Alteration (IHA 7.0) was employed to study the pre- and post-impact of a major flood event in 2014 at Sungai Dungun as well as the other anthropogenic stress such as sand mining activities that occurred at Sungai Dungun. The daily flowrate from the monitoring site at Jerangau bridge (Station Number: 4832441) was obtained from DID (Department of Irrigation and Drainage) to assess the pre-impact flowrate (2002 -2014) and post-impact flowrate (2015-2019). It was found that the flow duration curve decreased at the post-impact significantly compared to the pre-impact duration. The median flows dropped almost half between pre-impact and post-impact analysis. A few indicators were identified as the high range of variability approach (RVA) that defines the extent of alteration between pre- and postanalysis. The positive RVA of fall rate, high pulse duration, low pulse duration signifies the increase of frequency from pre-impact to the post-impact while negative RVA of 90-1-day minimum flows, 30-7 days maximum flows December, July and May median flow indicate the frequency of values in the category has decreased between pre- and post-analysis.
\end{abstract}

Keywords: Hydrological regime alteration, River flows, IHA 7.0, Range of variability approach, Sungai Dungun, Pre-and post-impact

\section{Introduction}

Human use of land and water has altered the terrestrial phase of the water cycle rendering rivers to hydrological variability and flow stress (Stewardson et al., 2017). Hydrological regime alteration is the modification of the pattern inflows of water, sediments, nutrients and regime of the rivers and streams. Usually, the patterns of rivers and streams are seasonally variable. However, it can be altered by both natural processes and human activities such as logging, land development at the riverbank, sand mining and flooding. Hydrological alterations may result in a decrease of hydro-morphological and ecological quality (Belletti et al., 2015). It also can cause a range of pressure on the aquatic ecosystem, changes in water quality, quantity, flow rate and temperature of the river, changes to the channel, bed erosion and deposition processes, flash floods and alter the availability of water in the riparian area (Carlisle et al., 2010).

Sungai Dungun at Terengganu endured significant sand mining activities based on onsite visit recently. Approximately 6 companies were extracting instream sand sediment within 12 kilometers of the river reach. Besides, the major flood in 2014 brought a significant amount of sediment load into the river system. The capacity of the river system to replenish and flush out the sediment load remains unknown. Sungai Dungun provides water abstraction for 
four water treatment plants namely Serdang, Tepus, Jerangau and Kemudi Water Treatment Plant (WTP). The occurrence of flow alteration at Sungai Dungun is disastrous due to the presence of the existing WTPs which acquire safe water yield from Sungai Dungun. Until today, there is no specific study on flow alteration at Sg Dungun except the ongoing research on Integrated River Basin Management (IRBM) study which was conducted by Department of irrigation and Drainage Malaysia beginning from 2019-2021.

Therefore, this research aimed to assess the hydrological regime alteration at Sungai Dungun, Terengganu using the Indicators of Hydrologic Alteration tool. The pre- and postimpact were set in December 2014 due to a significant flood event which brought a high amount of sediment load to the river system.

\section{Materials and Methods}

\section{Study Area}

Dungun is one of the districts in the state of Terengganu Darul Iman, and Kuala Dungun is the district capital. Sungai Dungun, with a catchment area of approximately $1875 \mathrm{~km}^{2}$, originates from the upper catchments of $\mathrm{Sg}$ Pertang, Sg Perlis, Sg Jengai and drains into South China Sea with its mouth situated on the east coast of Terengganu state, namely Kuala Dungun. Kuala Dungun currently houses the administrative capital of Dungun district and is accessible through major and minor road networks from either Kuala Terengganu or Kemaman. Sg Dungun endures two significant problems: river mouth siltation and flooding.

Based on Figure 1, it is evident that Sungai Dungun contains 14 significant feeder rivers from various sub-catchments. Kemudi and Serdang water treatment plants are located at the downstream part from the JPS water level and flow station. Thus, the measured flow is crucial to predict the water yield at both the water treatment plant. Table 1 shows the property of the water treatment plant and water level station for Sungai Dungun.

Table 1: Property of Water Treatment Plants and Hydrological Stations at Sungai Dungun

\begin{tabular}{lccc}
\hline \multicolumn{1}{c}{ Type } & River's name & Longitude & Latitude \\
\hline Kemudi WTP & Sg Dungun & $103^{\circ} 18^{\prime} 45^{\prime \prime}$ & $04^{\circ} 48^{\prime} 28^{\prime \prime}$ \\
Serdang WTP & Sg Dungun & $103^{\circ} 20^{\prime} 21^{\prime \prime}$ & $04^{\circ} 47^{\prime} 28^{\prime \prime}$ \\
Tepus WTP & Sg Dungun & $103^{\circ} 10^{\prime} 14^{\prime \prime}$ & $04^{\circ} 49^{\prime} 02^{\prime \prime}$ \\
Jerangau WTP & Sg Dungun & $103^{\circ} 12^{\prime} 15^{\prime \prime}$ & $04^{\circ} 50^{\prime} 35^{\prime \prime}$ \\
WL Station@Jambatan Jerangau & Sg Dungun & $103^{\circ} 12^{\prime} 15^{\prime \prime}$ & $04^{\circ} 50^{\prime} 35^{\prime \prime}$ \\
Flow Station@Jambatan Jerangau & Sg Dungun & $103^{\circ} 12^{\prime} 15^{\prime}$, & $04^{\circ} 50^{\prime} 35^{\prime \prime}$ \\
\hline
\end{tabular}




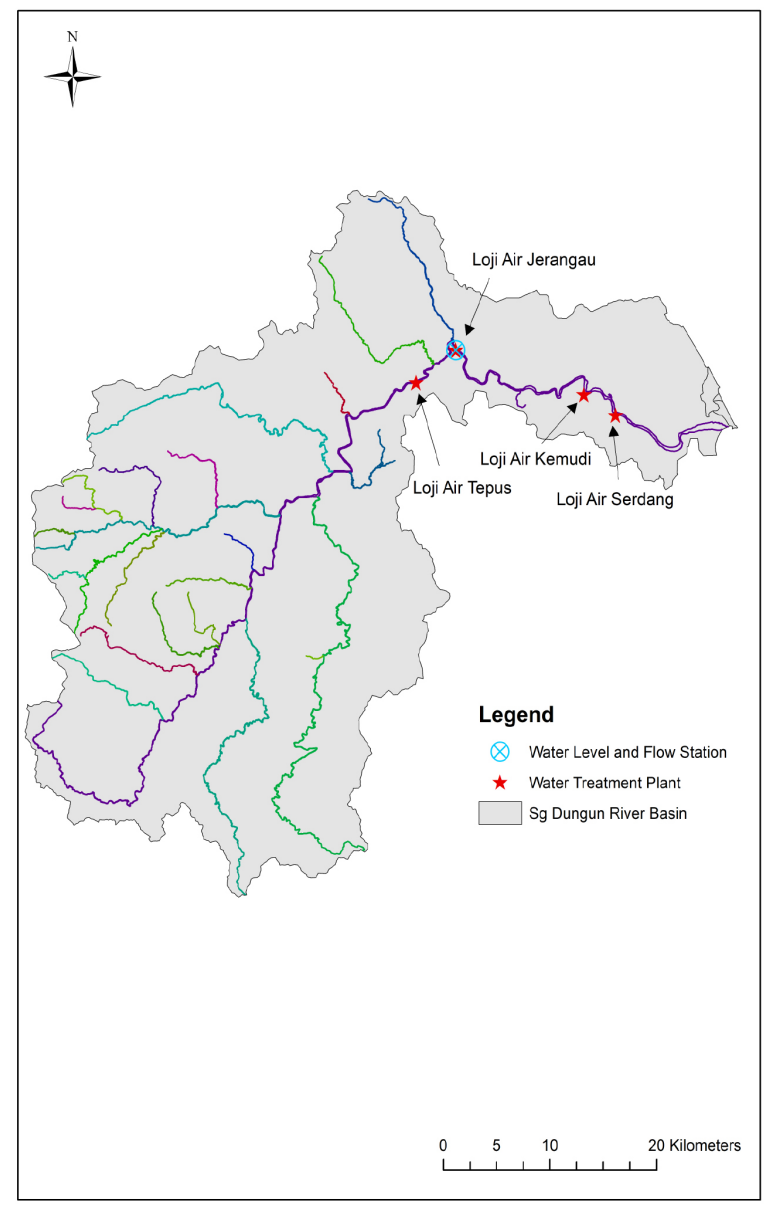

Figure 1: Distribution of River Networks along Sg Dungun

\section{Software and Datasets}

Indicators of Hydrologic Alteration(IHA) ver. 7.1 has been developed by The Nature Conservancy (TNC) as an easy-to-use tool for calculating the characteristics of natural and altered hydrologic regimes (The Nature Conservancy, 2009). The IHA parameters consist of 5 statistical groups as shown in Table 2 (Ritcher et al., 1996; Ritcher et al., 1997; Ritcher et al., 1998; Carlisle et al., 2010; Stewardson et al., 2017; Ali et al., 2019; Langat et al., 2019). 
Table 2: IHA Parameters (The Nature Conservancy, 2009)

\begin{tabular}{ll}
\hline \multicolumn{1}{c}{ IHA statistics group } & \multicolumn{1}{c}{ Hydrologic parameters } \\
\hline $\begin{array}{l}\text { The Magnitude of monthly water condition } \\
\text { The Magnitude and duration of annual extreme water } \\
\text { conditions }\end{array}$ & $\begin{array}{l}\text { Mean value for each calendar month } \\
\text { Annul minima(maxima) 1-day mean Annual } \\
\text { minima(maxima) 3-day means }\end{array}$ \\
Annual minima(maxima) 7-day means \\
Annual minima(maxima) 30-day means \\
Annual minima(maxima) 90-day means \\
The Timing of annual extreme water conditions & $\begin{array}{l}\text { Number of zero-flow days Base flow index: 7-day } \\
\text { minimum flow/mean flow for the year }\end{array}$ \\
(minimum) & Number of low (high) pulses within each water year \\
The Frequency and duration of high and low pulse & Mean duration of low (high) pulses (days) \\
The Rate and frequency of water condition changes & Rise (fall) rates: mean or median of all positive \\
& differences between consecutive daily values \\
\end{tabular}

The flow datasets were estimated at Jambatan Jerangau (daily) spanning from 1/1/2002 until 31/12/2019. Department of Irrigation and Drainage Ampang provided stage data $(\mathrm{m})$ for Sungai Jerangau for that period of study. The river discharge at Sungai Jerangau was obtained using the flow rating curve which was developed specifically for Sg Dungun@ Jambatan Jerangau station. The estimated flows were verified using actual flowrates as depicted in Table 3.

Table 3: Observed Hydraulic Geometry and Flowrates at Sg Jerangau

\begin{tabular}{lcccc}
\hline & Stage Height $(\mathrm{m})$ & River Discharge $\left(\mathrm{m}^{3} / \mathrm{s}\right)$ & Flow areas $\left(\mathrm{m}^{2}\right)$ & River Velocity $(\mathrm{m} / \mathrm{s})$ \\
\hline Number of Data & 96 & 96 & 96 & 96 \\
Coverage years & $2004-2016$ & $2004-2016$ & $2004-2016$ & $2004-2016$ \\
Min values & 4.240 & 6.960 & 30.840 & 0.095 \\
Max values & 13.00 & 7947.151 & 8899.600 & 1.416 \\
Average values & 6.199 & 232.645 & 277.628 & 0.551 \\
\hline
\end{tabular}

The flow rating curve formula was developed using polynomial fit which yield $\mathrm{R}^{2}=0.9006$. Figure 2 shows that the majority of flowrates sat at the lower tails; elucidated that the majority of actual flow measurements were sampled during normal flowrates or during recessing limb of a flow hydrograph. The relationship between stage height $(\mathrm{m})$ and river discharge $\left(\mathrm{m}^{3} / \mathrm{s}\right)$ can be deduced using the following polynomial equation:

$$
Q=28.99 x H^{2}-282.2 x H=709.96
$$

where $Q=$ river discharge $\left(\mathrm{m}^{3} / \mathrm{s}\right)$ and $H=$ stage height in (m). 


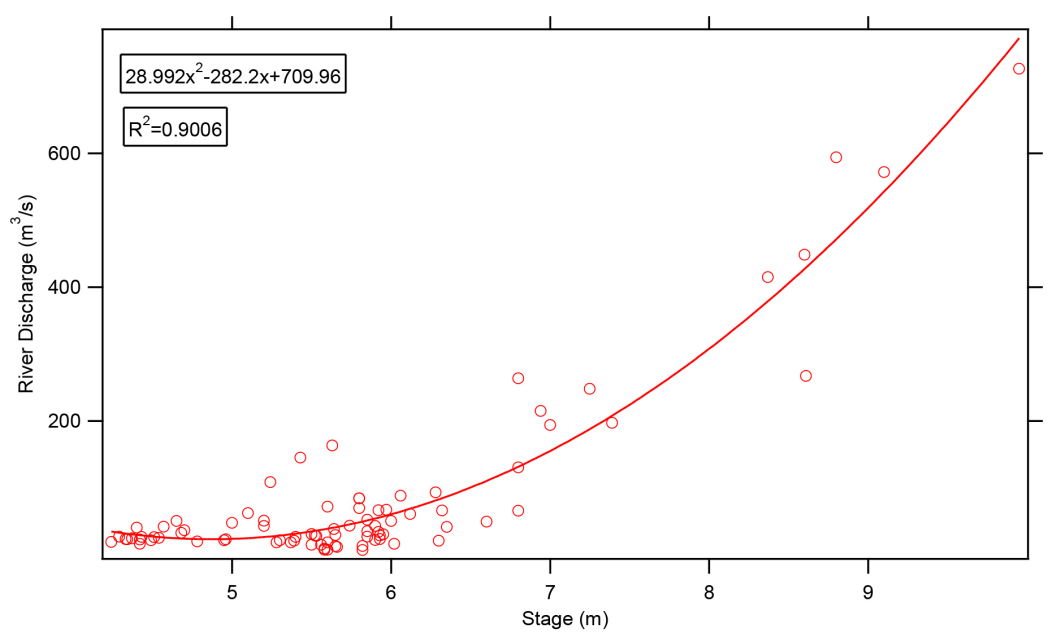

Figure 2: Flow rating curve for Jambatan Jerangau@Sg Dungun

Validation was made between the hold out sample (actual data) and estimated flows to elucidate the accuracy of rating curve equation for Sg Dungun@Jambatan Jerangau. The discrepancy ratio test was used to validate the estimated flows. The discrepancy ratio between the actual flows and estimated flows should fall within the ratio of $0.5-2.0$ to justify the reliability of proposed rating curve formula in equation 1 (Sinnakaudan et al., 2010; Sulaiman et al., 2019). The ratio of 1 depicts the unity between the measured flows and estimated flows. Figure 3 showed that majority of validated flows are within the range ( $>80 \%)$ which signify the reliability of rating curve formula.

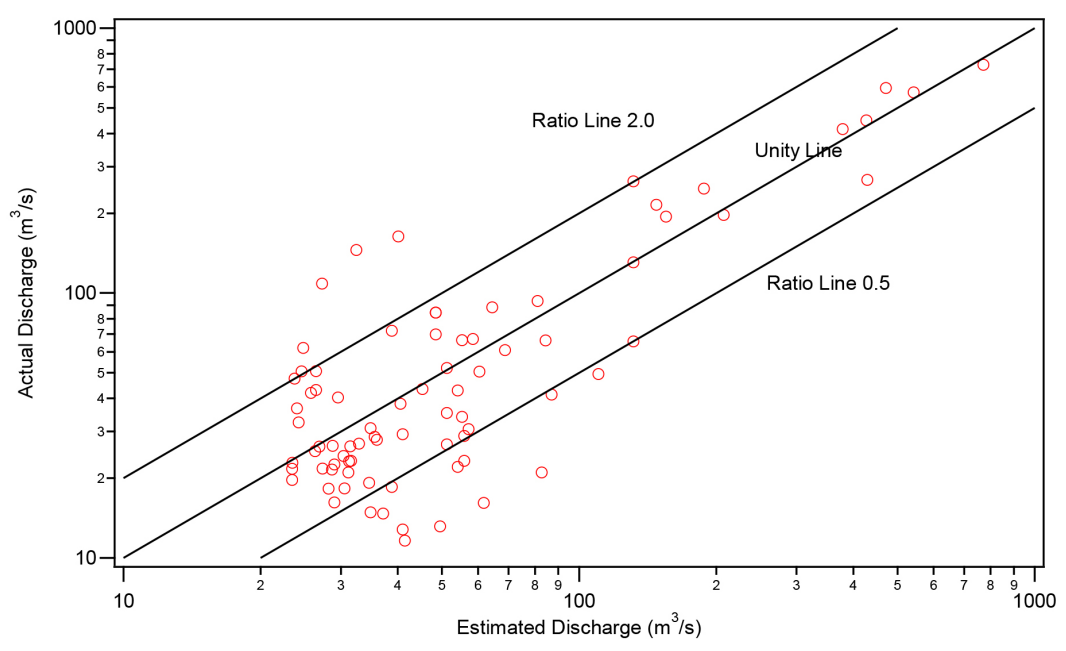

Figure 3: Discrepancy ratio test between actual discharge and estimated discharge

Other statistical analysis such as NashSutcliffe efficiency (NSE) showed the value of 0.901 which is close to 1 . The one-to-one relationship between observed flows and estimated flows (Figure 4) showed the same pattern which signify the reliance on rating curve formula. 


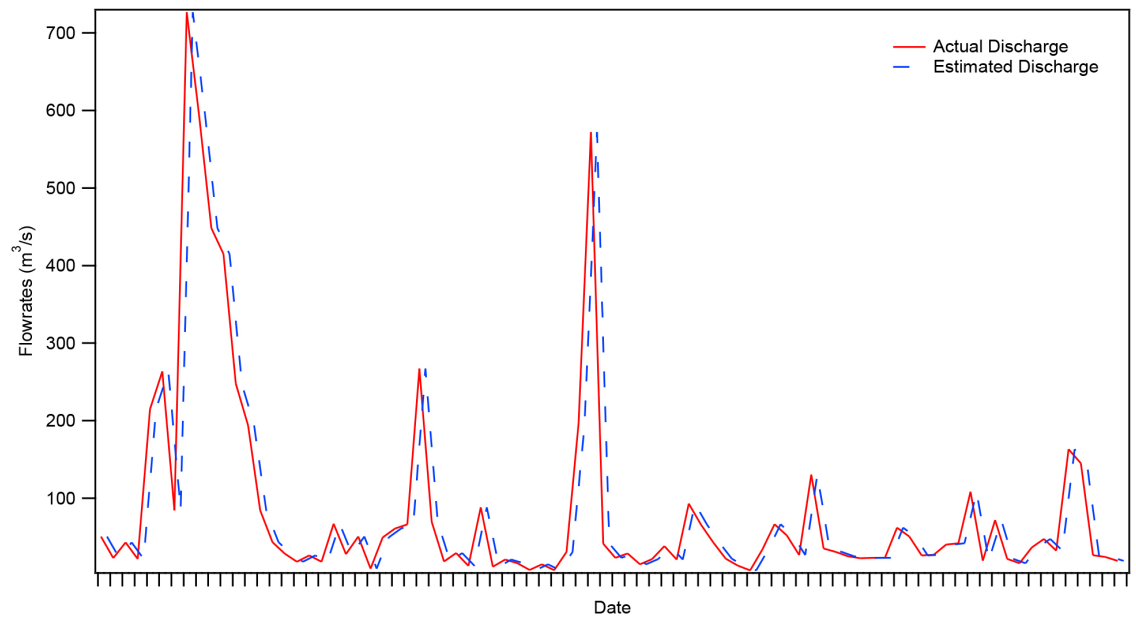

Figure 4: One-to-one plot between actual and estimated flowrate

\section{Method of Analysis}

The data were grouped in two main clusters: pre-impact from $2002-2014$ and post-impact scenario from 2015 - 2019. The threshold of 2014 was selected due to a major flood event during that year. The flow duration curve and
Range of Variability Approach (RVA) were assessed to observe the hydrological parameters that are susceptible to hydrologic alteration at Sungai Dungun. The whole flow hydrograph for Sg Dungun@Jambatan Jerangau is shown in Figure 5.

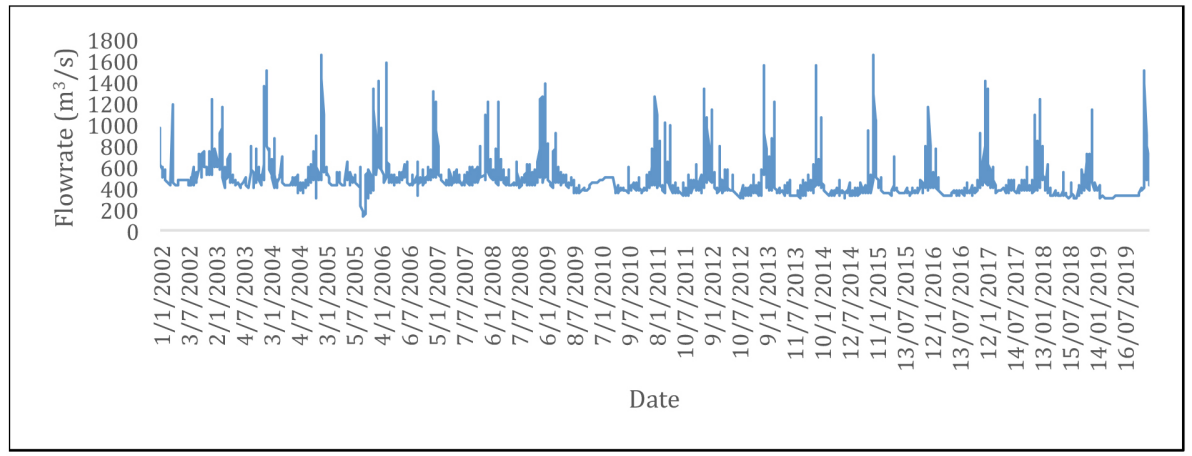

Figure 5: Daily streamflow at Jambatan Jerangau from 2002 until 2019

\section{Results and Discussion}

\section{Monthly Flows and Monthly Low Flows}

The mean monthly flows showed a systematic decreasing trend between pre-impact and postimpact scenarios as shown in Figure 6. The flows dropped across the water year where the mean monthly flows for $425 \mathrm{~m}^{3} / \mathrm{s}$ to $320 \mathrm{~m}^{3} / \mathrm{s}$ during the dry season (April). This trend is similar for the normal season (July) where the median line dropped between pre-impact and post-impact scenarios. Although a spike was recorded January (wet season), still the median values showed a decreasing trend between these two timeframes. The IHA computes parameters for five different types of Environment Flow 
Components (EFC) which are low flows, into a repeating set of hydrographic patterns that extreme low flows, high flow pulses, small are ecologically relevant. These five types of floods, and large floods. The description of flow events represented the flow condition that EFC's based on the research done by the must be maintained to sustain riverine ecological ecologists that river hydrographs can be divided integrity (The Nature Conservancy, 2009).
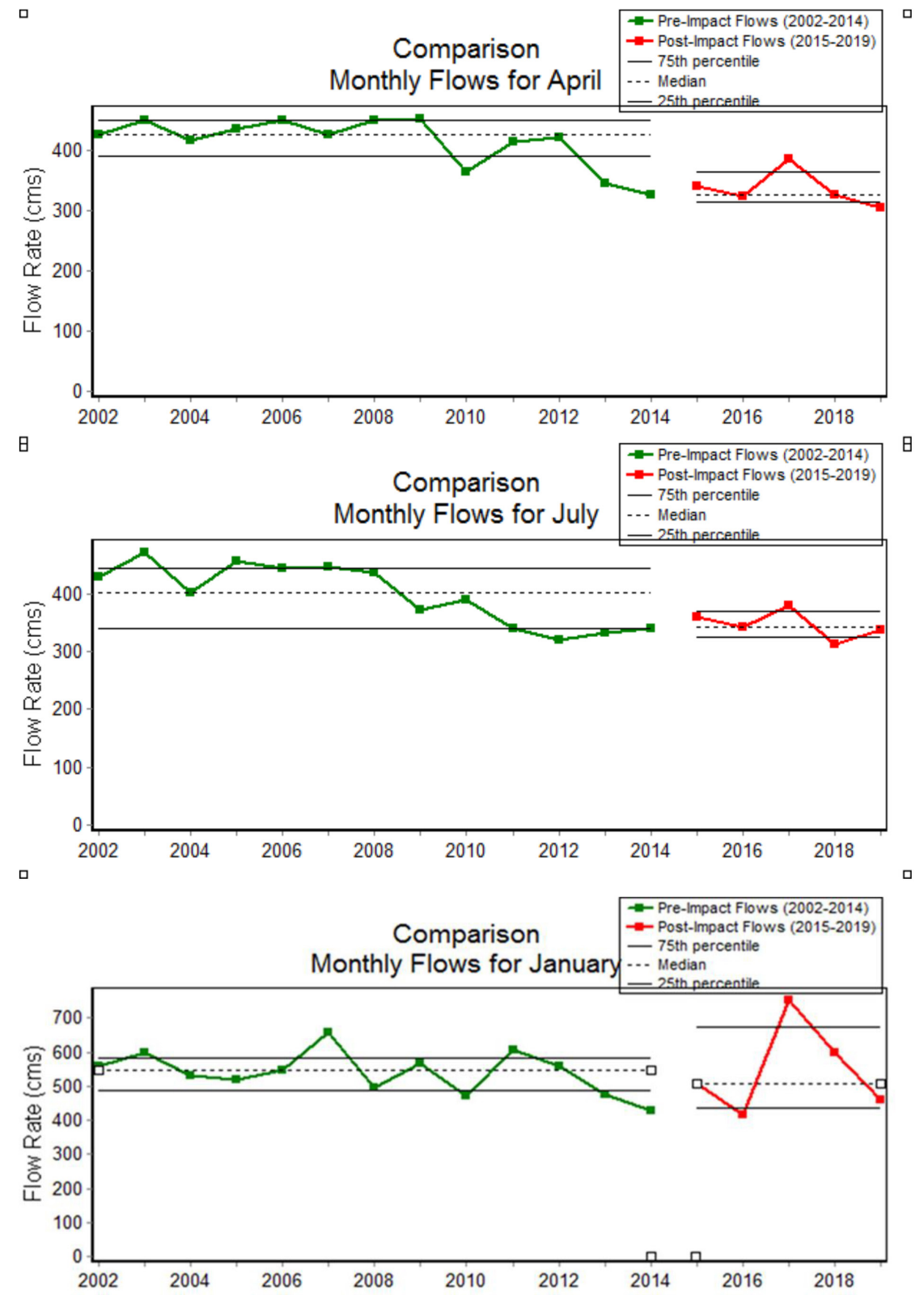

Figure 6: Monthly flowrate at Sg Dungun for the selected month 
口

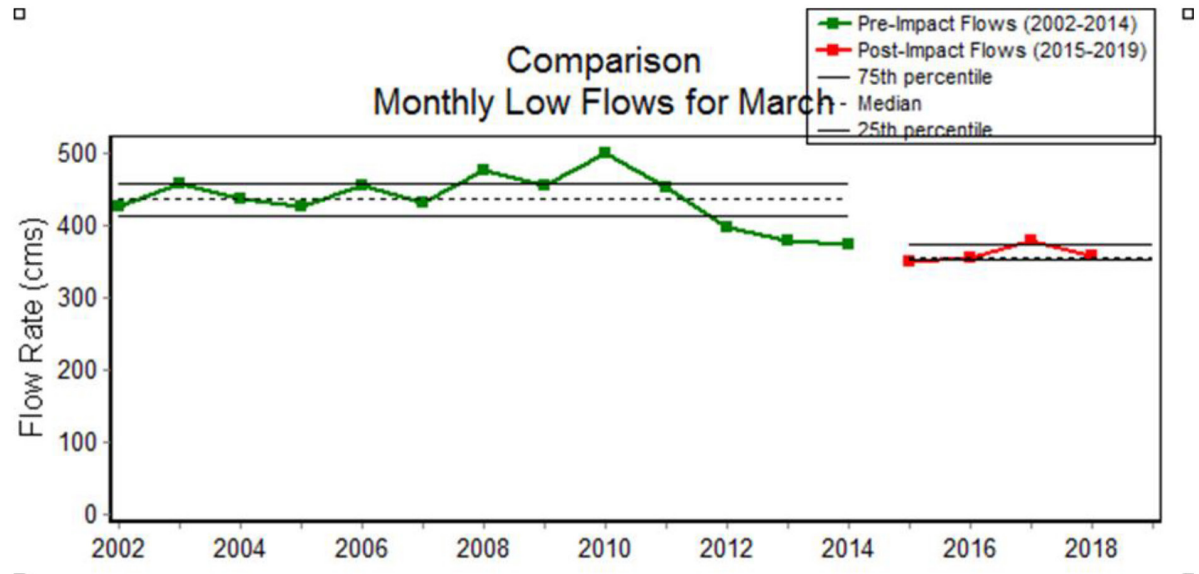

日

Comparison Monthly Low Flows for May - 75 th percentile

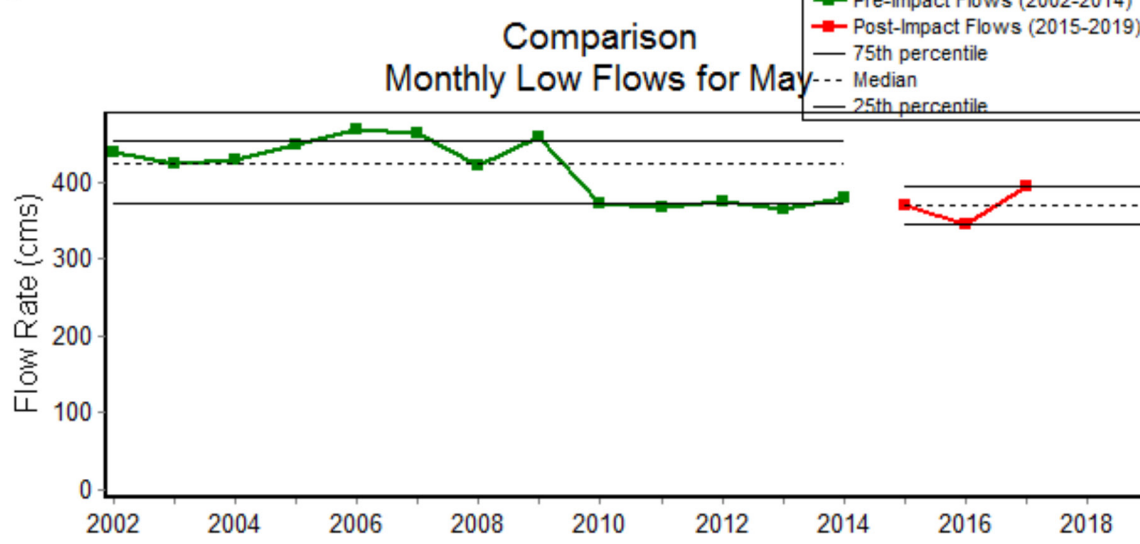

日

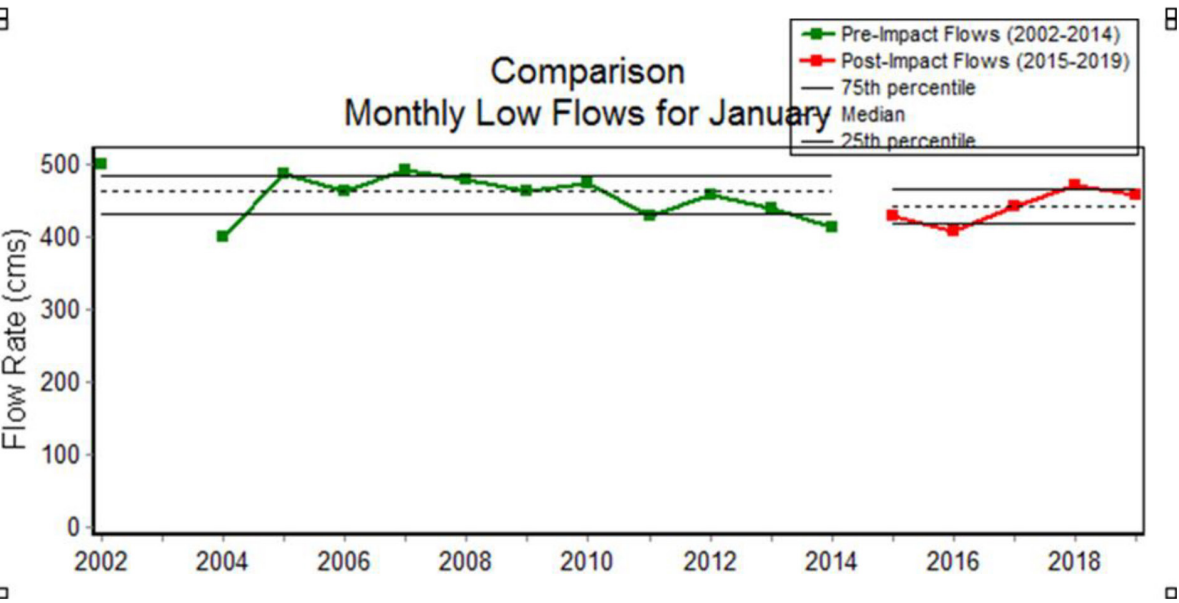

Figure 7: Monthly low flows at Sg Dungun for the selected month 
The monthly low flows depicted the same trend as the mean monthly flows (Figure 7). The baseflow pattern at post-impact hydrological years showing decreasing trend opposed to the pre-impact hydrological years. Low flows can be inferred as the dominant flow condition in most rivers. The river returns to its base- or low-flow level after a rainfall event or snowmelt period has passed and associated with surface runoff from the catchment has subsided (Carlisle et al., 2010). During low-flow levels, the river will be sustained by groundwater discharge. The low-flow level indicates the amount of aquatic habitat available for most of the year and it has a strong influence on the diversity and number of organisms that can live in the river (Stewardson et al., 2017).

\section{Flow Duration Curve (FDC)}

Flow duration curve (FDC) is a cumulative frequency curve that shows the percent of time specified discharges were equaled or exceeded during a given period (Subramanya, 2013). This graph consists of the flow rate of the river and its exceedance probability. The flow duration curve was used to determine the flow rate of the river that can cause a flood to that area or safe water yield for a water treatment plant (Gribbin, 2013). To characterize the information in the FDC, it was partitioned into different segments
(Langat et al., 2019). The first part representing high flows $(0-10 \%$ exceedance probabilities of flow) characterizing watershed water yield from high rainfall events, the second partition gives wet conditions (10-40\%) described by flows from medium size rainfall events and the third part being mid-range flows (40-60\%)

illustrated by flows from moderate rainfall events. The other segments were dry period conditions $(60-90 \%)$ related to the intermediate base flow relaxation response of the watershed water yield, and the low flows (90-100\%) related sustainability of streamflow in the longterm (see Figure 8). Based on the FDC graph, there is a difference in flow rate between the pre-impact period and post-impact period of Sungai Dungun at $10 \%$ of exceedance. During the pre-impact period, the flow rate of the river at $10 \%$ of exceedance is $632.5 \mathrm{cms}$ while during post-impact is $510.5 \mathrm{cms}$. It can be concluded that the river carrying capacity is lower than it should be after the 2014 flood event. Sungai Dungun might be choked with sedimentation along with its longitudinal profile. For a safe water yield, it is convenient to obtain flow at $70 \%$ exceedance probability (Gribbin, 2013) to ensure the sustainability of water abstraction at WTP. The FDC decreasing between the pre- and post-impact which render the lowerthan-expected flow rate and water depth for the majority of water year at Sungai Dungun.
口

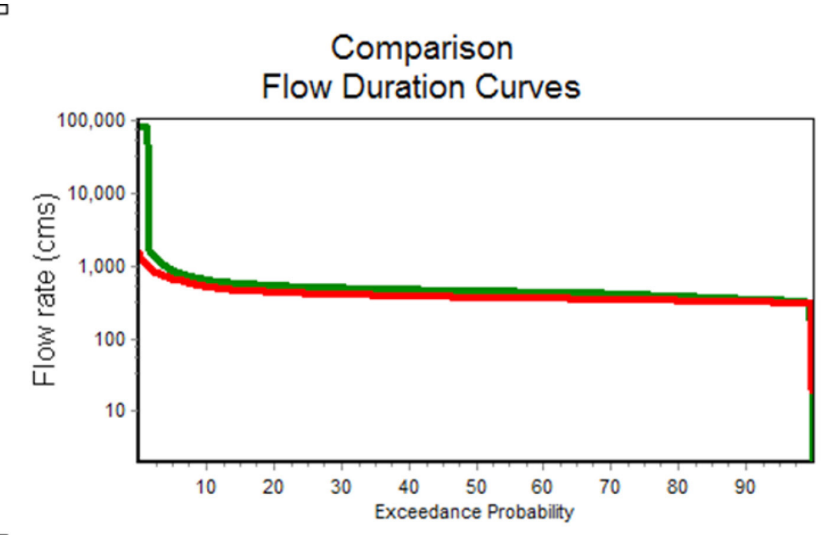

V Annual (2002-2014) Annual (2015-2019)

Figure 8: FDC at Sungai Dungun 


\section{Range of Variability Approach (RVA)}

When analyzing the change between two time periods (or comparing two Hydro Data files), the IHA software enables users to implement the Range of Variability Approach (RVA) described in Ritcher et al. (1997). The pre-development variation can also be used as a basis for defining initial environmental flow goals (The Nature Conservancy, 2009). The eventual RVA analysis is the formulation of Hydrologic Alteration factor of either + ve or -ve values. A positive Hydrologic Alteration value means that the frequency of values in the category has

increased from the pre-impact to the postimpact period (Ritcher et al., 1998), while a negative value means that the frequency of values has decreased (Ritcher et al., 1998). There are three categories of RVA: 1) low hydrologic alteration factor (in yellow); 2) middle hydrologic alteration factor (in green) and 3) high hydrologic alteration factor (in red). In can be concluded from Figure 9 that 16 parameters show high RVA alteration namely April-, Julyand December- median flows, 1-, 3-, 7-, 30and 90-day minimum flow, 1-, 3-, 7-, 30- and 90-day maximum flow, date of maximum flow, low pulse duration, high pulse duration, fall rate and the number of reversals. These hydrological statistics endured a discrepancy between observed and expected frequency (pre- and postimpact) of greater than the 67 th percentile. The lowest category contains all values less than or equal to the $33^{\text {rd }}$ percentile; the middle category contains all values falling in the range of the 34 th to $67^{\text {th }}$ percentiles.

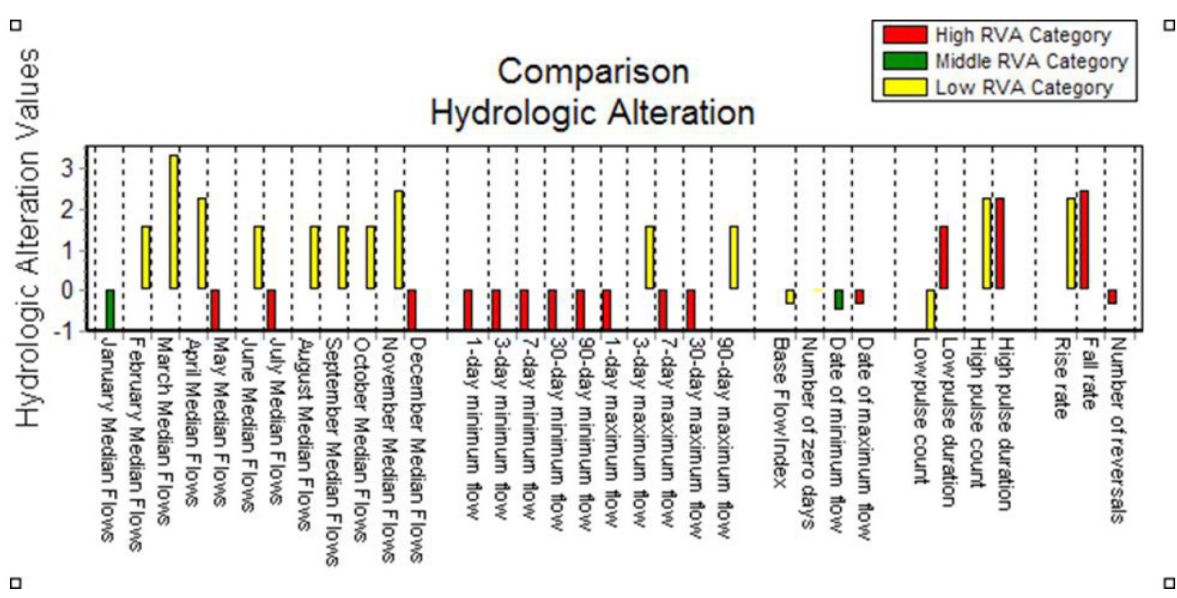

Figure 9: Hydrologic alteration values at $\mathrm{Sg}$ Dungun

\section{Conclusion}

The safe water yields and flow regimes at Sungai Dungun must be preserved for water abstraction at water treatment plants. The findings that we have presented suggest that the flows at Sungai Dungun have been altered and showed the trend of decreasing at pre- and post-impact analysis. The median flows, first quartile and third quartile for each month are dropped significantly. The baseflow or low flow which is dominant throughout the water year is dropped as well.
The flow duration curve showed a decreasing trend between the pre- and post-impact which rendered the lower-than-expected flow rate and water depth for the majority of water year at Sungai Dungun. While this study does not offer a conclusive answer to the question of "what makes flow at Sungai Dungun altered?", it does give a proven analysis that flows at Sungai Dungun have decreased and are in dire need of rectification.

An initial anticipation on the main cause of flow alteration at Sungai Dungun is the 
sedimentation issues which lowering the river carrying capacity than it should be. Therefore, it is recommended to carry out research study on the erosion and sedimentation to rectify the main cause of flow alteration at Sungai Dungun.

\section{Acknowledgements}

A special thanks to JPS Ampang for providing streamflow datasets at Jambatan Jerangau, Dungun Terengganu.

\section{References}

Ali, R., Kuriqi, A., Abubaker, S., \& Kisi, O. (2019). Hydrologic Alteration at the Upper and Middle Part of the Yangtze River, China: Towards Sustainable Water Resource Management Under Increasing Water Exploitation. Sustainability, 11(19), $1-16$.

Belletti, B., Rinaldi, M., Buijse, A. D., Gurnell, A. M., \& Mosselman, E. (2015). A review of assessment methods for river hydromorphology. Environmental Earth Sciences, 73(5), 2079-2100. doi:10.1007/ s12665-014-3558-1

Carlisle, D. M., Falcone, J., Wolock, D. M., Meador, M. R., \& Norris, R. H. (2010). Predicting the natural flow regime: models for assessing hydrological alteration in streams. River Research and Applications, 26(2), 118-136.

Gribbin, J. E. (2013). Introduction to Hydraulics \& Hydrology: With Applications for Stormwater Management: Cengage Learning.

Langat, P. K., Kumar, L., Koech, R., \& Ghosh, M. K. (2019). Hydro-Morphological Characteristics Using Flow Duration Curve, Historical Data and Remote Sensing: Effects of Land Use and Climate. Water, 11(2), 309.

Ritcher, B. D., Baumgartner, J., Wigington, R., \& Braun, D. (1997). How much water does a river need? Freshwater Biology, 37(1), 231-249.
Ritcher, B. D., Baumgartner, J. V., Braun, D. P., \& Powell, J. (1998). A spatial assessment of hydrologic alteration within a river network. Regulated Rivers: Research \& Management: An International Journal Devoted to River Research and Management, 14(4), 329-340.

Ritcher, B. D., Baumgartner, J. V., Powell, J., \& Braun, D. P. (1996). A method for assessing hydrologic alteration within ecosystems. Conservation Biology, 10(4), 1163-1174.

Sinnakaudan, S. K., Sulaiman, M. S., \& Teoh, S. H. (2010). Total bed material load equation for high gradient rivers. Journal of Hydro-environment Research, 4(3), 243-251. doi:https://doi.org/10.1016/j. jher.2010.04.018

Stewardson, M. J., Acreman, M., Costelloe, J. F., Fletcher, T. D., Fowler, K. J., Horne, A. C., ... Peel, M. C. (2017). Understanding hydrological alteration. In Water for the Environment (pp. 37-64): Elsevier.

Subramanya. (2013). Engineering Hydrology: McGraw Hill Education (India) Private Limited.

Sulaiman, M. S., Abood, M. M., Sinnakaudan, S. K., Shukor, M. R., Goh, Q. Y., \& Chung, X. Z. (2019). Assessing and Solving Multicollinearity in Sediment Transport Prediction Models using Principal Component Analysis. ISH Journal of Hydraulic Engineering, 10.1080/0971501 0.09712019 .01653799 . doi:10.1080/09715 010.2019 .1653799

The Nature Conservancy. (2009). Indicators of Hydrologic Alteration Version 7.1 User's Manual. Retrieved from http://www.conservationgateway.org/ ConservationPractices/Freshwater/ EnvironmentalFlows/MethodsandTools/ IndicatorsofHydrologicAlteration/Pages/ IHA-Software-Download.aspx 
